Revista de Matemática: Teoría y Aplicaciones 2005 12(1 \& 2) : 129-138

CIMPA - UCR - CCSS ISSN: 1409-2433

\title{
TERM STRUCTURE OF INTEREST RATES
}

\author{
Benito A. Stradi*
}

Received/Recibido: 13 Feb 2004

\begin{abstract}
The risk free rate on bonds is a very important quantity that allows calculation of premium values on bonds. This quantity of stochastic nature has been modeled with different degrees of sophistication. This paper reviews the major models utilized in the estimation of the risk free rate and gives an example of the behavior generated by one of these models.
\end{abstract}

Keywords: Interest Rates, Term Structure, Stock Dynamics.

\section{Resumen}

La tasa de interés de un Banco Estatal para sus bonos comerciales es una cantidad muy importante porque permite el cálculo del interés adicional proveído por un bono comercial. Esa tasa de interés estatal, que no tiene riesgo para el inversionista, ha sido modelada con diferentes niveles de sofistificación. Este artículo compila y compara los principales modelos utilizados en la estimación de esa tasa libre de riesgo y da un ejemplo del comportamiento generado por uno de esos modelos.

Palabras clave: Tasas de Interés, Estructura de Tasas de Interés, Dinámica de Acciones Mathematics Subject Classification: 91B28

\section{Introduction}

The risk-free interest rate is one of the most fundamental and important variables in the financial markets. In a period of twenty-five years, a number of models have attempted to reproduce the yield curve of risk-free bonds. Amongst the multiple models the complexity increases as more variables are taken into account. These variables are economic parameters, beliefs in future states of the world, preferences and others. However, to date, there

\footnotetext{
${ }^{*}$ Department of Materials Science and Engineering, Institute of Technology of Costa Rica, Apdo. 1597050, Cartago, Costa Rica. E-Mail: bstradi@nd.edu
} 
is no agreement on any one model, and consequently, we lack a single universal approach to model the yield curve. My objective is to discuss the current knowledge on the term structure of interest rates beginning with the flat term-structure. This is discussed in relation to the Macaulay duration (1938). The need for more elaborate models is then introduced. The major hypotheses explaining the profile of the term structure are presented: expectations, market segmentation, liquidity premium and preferred habitat. The hypotheses provide no defined model. We look at alternative quantitative models that use the underlying controlling factors in the hypotheses. These divide into equilibrium and arbitrage models. The former have a stronger theoretical found and need more information; the latter are adjusted to specific data and may have some equilibrium foundation. There are single, two and multifactor models for which representative examples are given with emphasis on the models by Vasicek (1977), Cox, Ingersoll and Ross (1985), Brennan and Schwartz (1979) and Heath, Jarrow and Morton (1992). Duration is revisited to show an application in specifying a stochastic duration based on the Cox, Ingersoll and Ross model (1985). Finally, a term structure is simulated with the Vasicek's (1977) model to emphasize the practical applications of studying the yield curve.

\section{Theories}

The term structure of interest rates comprises the interest rates of risk-free zero-coupon bonds with sequential maturity dates. Default free bonds are considered those issued by a government in local currency (i.e. Treasury bonds). The risk-free interest rate and its volatility are key variables underlying the value of interest rate options and optimal hedging strategies.

A flat yield curve is the simplest of term structures, which predicts a constant yield for any maturity. This term structure, although not realistic, is uselful in the work of Macaulay (1938). He computes the variations of the price of a bond as a function of the interest rate and introduces the concept of duration. Standard immunization matches the durations of liabilities with those of portfolios to hedge risk. (Cuthbertson and Nitzsche 2001). Macaulay duration is only a valid measure of risk for parallel shifts of a flat yield curve. Unfortunately, in most applications the term structure is short-term mean-varying and stochastic in shape.

Actual term structures of interest rates share similar characteristics. Chapman and Pearson (2001) look at one-month Eurodollar rate and Federal funds rates of maturity from 1 to 30 years. They find both that the short rate of risk-free bonds spends long, consecutive periods above and below the overall mean, and that the volatility is also time varying and deviates from its long-run mean. Yan (2001) indicates that yield curves are generally upward sloping and in some cases downward sloping or humped.

Hypotheses to explain the nature of the term structure provide qualitative descriptions of the underlying important variables. Cuthbertson (2001) and Cox, Ingersoll and Ross (hereafter, CIR) (1985) concur in the discussion of four major hypotheses: expectations, market segmentation, liquidity preference and preferred habitat. The expectation hypothesis asserts that bonds are priced so that implied forward rates are equal to the expected 
spot rates (Brennan and Schwartz, 1979). It implies that the return on a long-term bond is equal to the expected return on a series of short-term bonds, or similarly that bonds of all maturities will render the same yield over the next holding period. The market segmentation hypothesis indicates that individuals have strong preferences for bonds of particular maturities. As a result, bonds of different maturities have specific clienteles (and trade in separate markets). An immediate weakness of this theory is the assumption that bonds with similar maturities will not approximate perfect substitutes. Under this hypothesis, long-term bonds are not necessarily more risky than short-term bonds because investors have a long-term investment horizon and no liquidity premium is needed to encourage purchase of long-term bonds (Brennan and Schwartz, 1979). The liquidity preference hypothesis asserts that long-term bonds are riskier than short-term bonds. Consequently an investor will demand a higher return in compensation for the risk undertaken with long-term bonds. Under this hypothesis, the forward rates are always larger than the corresponding expected future spot rates. The difference between them is the liquidity premium demanded by the risk-averse investor. Finally, the preferred habitat hypothesis asserts that investors have well-defined maturity preferences and do not require any liquidity premiums (similar to the market segmentation hypothesis). Moreover, this clientele is characterized with specific timing of their consumption. This may not seem entirely rational because it may exclude good possibilities of investments; however, the investor is not required by the market to be rational. We can find that the clienteles mentioned in these theories may indeed exist, and they are not purely theoretical. An example is found in the application of optimal strategies to minimize the tax burden on investments. Constantinides and Ingersoll (1984) indicate that there are tax clienteles who prefer specific bonds. Their findings are equally applicable to banks, bond dealers and individuals. The preferences are determined according to specific optimal bond-trading strategies. These strategies incorporate transactions costs and conform to the tax code. They differ substantially from the simple buy-and-hold and continued-realization policies, which would bias the estimation of the yield curve and the implied tax bracket of the investor. Black and Karasinski (1991) develop a model to maximize the bond value options for the investor taking into account taxes on ordinary income, capital gains and capital losses.

The hypotheses lack a quantitative model that uses past and current values to predict instantaneous risk-free rate of interest or the liquidity premium. In establishing quantitative models there are two major approaches: equilibrium and arbitrage. They differ in theoretical foundations and the amount of information needed to estimate the riskfree rate for zero-coupon bonds. Equilibrium models are those based on macroeconomic arguments. These models specify the market price of risk, obtain parameters by using historical data, and are generally used by economists (Yan, 2000; Heath, Jarrow and Morton, 1992). Arbitrage models are phenomenological; they include those variables, known from practice, to greatly affect the shape of the term structure. The models are calibrated to best-fit market data, are preferred by traders, and may take a structure similar to that of equilibrium models. The connection between the risk-free rate and the real-world rates is established through the market price of risk (Yan, 2000).

Equilibrium and arbitrage models are important and they have strengths and weaknesses. Equilibrium models have clear disadvantage because future rates need not follow 
previous historical trends, the most dramatic case would be during structural breaks in the economy. Similarly arbitrage models are weaken if the data used in the calibration is not suitable to predict future changes. Lonfstaff and Schwartz (1992) indicate that an advantage of equilibrium models is that the term structure, its dynamics, and the functional form of the market price of risk are obtained as a part of the equilibrium modeling. Cox, Ingersoll and Ross (1985) based their equilibrium model on some underlying key elements in the hypotheses, namely risk preferences and investment alternatives. They use a constant relative risk aversion utility function in their model; consequently the risk-free rate and risk factor premiums do not depend on wealth. This leads to a considerable simplification of the equations, but reduces the applicability of their model. Brennan and Schwartz (1979) argue that equilibrium models need too much information about tastes, endowments, production opportunities, and beliefs about future states of the world to formulate a model. Sundaresan (1984) studies consumption and equilibrium rates in stochastic production economies and finds that the choice of assumptions about technology and number of goods in the economy are crucial in determining the properties of equilibrium interest rates. Brennan and Schwartz (1979) assert that an advantage of arbitrage models is that they generally require less information than equilibrium models. Yan (2000) indicates that arbitrage models will not spot mispricing in the underlying bond information used in their calibration what is relevant for pricing derivatives. Longstaff and Schwartz (1992) argue that arbitrage models provide no guidance as to the form of the interest rate risk premiums. They claim that (in two factor term structure models) this ambiguity can lead to arbitrage opportunities. This reinforces the point by Yan (2000) in the case where underlying assets are mispriced and still used to calibrate arbitrage models.

The main characteristic of the term structure of interest rate is the stochastic behavior. There are single, two and multifactor models based on equilibrium and arbitrage arguments. The simplest models use one state variable to compute the dynamics of the risk-free zero-coupon bond interest rate. In general, these simple models permit closed form solution to the stochastic differential equation characterizing the term structure (Chan, Karolyi, Longstaff and Sanders (hereafter, CKLS), 1992). Predicted interest rates, in these models, are driven by the instantaneous rate of interest (Chapman and Pearson, 2001; Bali, 2000). A number of these models and their variations are nested in the following stochastic differential equation (CKLS, 1992),

$$
d r=(\alpha+\beta r) d t+\sigma r^{\gamma} d z
$$

where $r$ is the instantaneous risk-free interest rate, $z$ is the stochastic Gauss-Wiener process (i. e. $d z=\sigma \sqrt{d t}$ ), $t$ is the time, $\alpha+\beta r$ is the instantaneous drift rate, $\sigma r^{\gamma}$ is the instantaneous diffusion rate, the quantities $\alpha, \beta, \sigma$ and $\gamma$ are constant parameters in the five models. However, more complex dynamic equations assign functionalities to the parameters. CKLS (1992) compare a number of models described by equation (1) in their capacity to describe the term structure of the volatility. Their argument is that volatility is a key variable in valuing contingent claims and devising optimal hedging strategies. They use one-month Treasury bill yields and find that the value of the exponent, $\gamma$, is the most important parameter. Models with $\gamma>>1$ capture the dynamics of the shortterm interest rate better than those for which $\gamma<1$. Models with $\gamma<1$ are statistically 


\begin{tabular}{c|cccc}
\hline \hline Model & \multicolumn{4}{|c}{ Parameter } \\
& $\alpha$ & $\beta$ & $\sigma$ & $\gamma$ \\
\hline Merton & Constant & 0 & Constant & 0 \\
Dothan & 0 & 0 & Constant & 1 \\
Vasicek & Constant & Constant & Constant & 1 \\
CIR (1985) & Constant & Constant & Constant & $\frac{1}{2}$ \\
CIR (1980) & Constant & Constant & Constant & $\frac{3}{2}$ \\
\hline \hline
\end{tabular}

Table 1: Parameters for single factor risk-free rate models

rejected. They also point out that prediction differences between the models with the same $\gamma$ are smaller then those between model with different $\gamma$. Their unconstrained estimate of $\gamma$ is 1.5. Their volatilities were highly sensitive to the level, $r$, of the instantaneous risk free rate, $r$. The level of the risk free rate is the difference between the long-run mean and the current value of the rate. Chapman and Pearson's (2001) evidence indicate that the value of $\gamma$ is between 1.5-2.0 in absence of a temporary break and of 0.948 when a break occurs. CKLS (1992) find that the proportion of total variation in volatility captured by various models ranges from $5.46 \%$ for the CIR (1985) model to the $20.49 \%$ for the CIR (1980) model.

The models by Merton (1973), Dotham (1978), Vasicek (1977), and CIR (1985) are examples of the arbitrage (Vasicek, 1977; Dotham, 1978) and equilibrium models (Merton, 1973; CIR, 1985) in the literature. Merton's equilibrium model (1973) describes stock price dynamics for European options. His final result is a second order differential equation for the option price function in terms of the return on common stock, return on bond and maturity of the bond. Dotham (1978) presents a purely stochastic model, a detailed solution, an analytical term-structure equation for the instantaneous risk-free rate of interest and shows that the model would predict decreasing bond prices with increasing bond maturities. The Vasicek model (1977) is widely discussed in the literature. This model assumes that the markets are efficient, the short-rate is mean reverting and the instantaneous drift is linear. The structure of the dynamics permits an analytical determination of the term structure. The model can predict monotonic (upward and downward sloping) and non-monotonic (humped) term structures. However prediction of negative interest rates is possible; and this is a problem for interest-rate derivatives based on the price of a discount bond. Longstaff and Schwartz (1992) indicate that the model implies both a perfect correlation between all bonds when in reality, only bonds of similar maturity time are highly correlated. Bond prices decrease monotonically with increasing short-term riskless rates. The linear drift implies that the strength of the mean reversion is the same at all levels of the short rate. This is an issue for Chapman and Person (2001) who argue that there is no theoretical basis to specify how the short rate should mean-revert. Consequently, a misspecification of the mean reversion term could affect the functionality assigned to the diffusion term. Schroder (1989) indicates his constant elasticity model $(\alpha)$ to work better with data that is not more than one month old. The CIR model (1985) 
has mean-reverting drift, variance proportional to the level of interest rate and permits analytical solutions for bond prices and bond options. No negative short rates are predicted and evidence suggests the need for a more complex short-rate volatility structure (Yan, 2001). Bond prices decrease monotonically with increasing interest rates (Longstaff and Schwartz, 1992). CKLS (1992) and Chapman and Person (2001) agree that the evidence indicates that mean reversion in short rates is weak; this excluding extreme values because there are generally few extreme points to present a sound conclusion including them. Longstaff (1989) present a term structure where bond prices are not linearly dependent with interest rates. It can generate humps, monotone and troughs topologies. In his model, an increase in interest rate need not always result in an increase in bond price. It is different form equation (1) in that the instantaneous drift is proportional to the square root of the instantaneous rate. The diffusional term is the same as that in CIR (1985). His model outperforms the CIR's (1985) model in describing actual Treasury bill yields for the 1964-1986 period. It is similar to CIR (1985) and Vasicek (1977) in that the stochastic interest rate is elastically drawn toward a central value.

Jeffrey (1995) points out that in single factor models model the instantaneous interest rates are Markovian because they assume that all the information needed to drive the dynamics of the term structure is contained in that variable. Chapman and Pearson (2001) indicate that research shows that at least three factors are needed to capture the variability of the term structure: level $(r)$, slope and curvature. They also note that from previous studies about ninety percent of the variation in US Treasure rates can be explained by changes in the general level of interest rates and nine percent by the slope and curvature.

A consequence of these findings is that the large body of literature on single factor models is simply a detailed examination of the first contributing factor to the term structure. The short rate volatility is slightly different with eighty percent dynamics explained by the level of interest rates and twelve percent by slope and curvature. Multifactor models take into account at least two factors to determine the term structure. The Brennan and Schwartz model $(1979,1980)$ is a two-factor arbitrage model. The factors are the short rate, $r(t)$, and the consol yield, $l(t)$. The corresponding stochastic differential equations are

$$
\begin{aligned}
& d r=\beta_{1} d t+\eta_{1} d z_{1} \\
& d l=\beta_{2} d t+\eta_{2} d z_{2}
\end{aligned}
$$

The instantaneous drift parameters, $\beta_{1}$ and $\beta_{2}$, and the volatilities, $\eta_{1}$ and $\eta_{2}$, are functions of the variables $r(t), l(t)$ and $t$. The stochastic terms, $d z_{1}$ and $d z_{2}$, are correlated Gauss-Wiener processes. The consol yield, $l(t)$, is defined as the yield on a bond that has a constant continuous coupon and infinite maturity (Schwartz and Schaefer, 1994), this is the long term rate (Yan, 2001). The model implies two market prices of risk one associated with $l(t)$ and the other with $r(t)$ (Yan, 2001). The inputs are the functionalities of the market prices of risk, drift and volatility terms. The term structure generated is of practical significance. Schaefer and Schwartz (1994) modify this model to use as variables the consol rate, $l(t)$, and the spread, $s=r(t)-l(t)$. 
Longstaff and Schwartz (1992) in their discussion of two factor general equations (the two factors are $r$ and $\sigma$ ) models indicate that explicit dependence of yields on the interest rate volatility allow the model to predict humps and troughs of the term structure, the relation between term premium, and interest rate volatility. Other models cited by Yan (2001) are those by Hoo-Lee, and Hull and White with variations such as that by Black and Karasinski (1991).

An important multifactor model is that by Heath-Jarrow-Morton (hereafter HJM) (1992). This model has a generic drift term together with a family of shocks. This is,

$$
d f(t, T)=\alpha(t, T) d t+\sum_{i=1}^{N} \sigma_{i}(t, T) d z_{i}(t)
$$

where $d f(t, T)$ is the instantaneous forward rate maturing at time $T$ measured at time $t$. The parameters $\alpha$ and $\sigma_{i}$ are stochastic functions. The HJM model focuses on dynamic transitions of the whole term structure rather than on particular economic variables (Jeffrey, 1995). This is an arbitrage model that uses an initial term structure, and volatility information as input. Interest rates present a path dependency through the volatility term, non-Markovian spot rates (Jeffrey, 1995). Long-term problems may result in large computational overhead, which can be handled by parallel processing. A major point of concern is that uncertainties in the initial term structure could cause prediction of negative interest rates. This equation was originally derived to price interest rate sensitive contingent claims given the prices of all zero coupon bonds (HJM, 1992). Bond pricing is constrained by a non-arbitrage condition. The connection of the HJM (1992) formulation to bond pricing is through the following equation,

$$
\ln (P(t, T))=-\int_{t}^{T} f(t, v) d v
$$

where $P(t, T)$ is the price of a one dollar face value, default-free, zero-coupon bond at time $t$ that will mature at time $T$. The instantaneous forward rate at time $t$ and date $t$ is the instantaneous spot rate of interest at time $t$, this is, $f(t, t)=r(t)$. If the HJM model is subject to Markovian spot interest rates then the volatility and the drift structures are not independent (Jeffrey, 1995). This provides further evidence to the point made by Chapman and Pearson (2001) that if the drift functionality is misspecified then the volatility term is also affected. The most promising models to date are the multifactor models, however, they are more difficult to implement.

It is interesting to briefly explore the application of one of these models. CIR (1979) derived a stochastic duration formula with units of time. This is similar to Macaulay duration in that it can be used to hedge risk. Their short rate dynamics and bond price are given by

$$
\begin{gathered}
d r=\beta(\mu-r) d t+\sigma r^{\frac{1}{2}} d z \\
P(r, T)=F(T) e^{-r G(T)}
\end{gathered}
$$


where $r$ is the (zero-coupon, risk-free, instantaneous) interest rate, the parameters $\beta, \mu$, $\sigma$ are constant, and the functions $F(T)$ and $G(T)$ are defined as follows,

$$
\begin{aligned}
F(T) & =\left\{\frac{2 \gamma e^{(\gamma+\beta-\pi) T / 2}}{(\gamma+\beta-\pi)\left(e^{\gamma T}-1\right)+2 \gamma}\right\}^{\frac{2 \beta \mu}{\sigma^{2}}} \\
G(T) & =\frac{2}{\beta-\pi+\gamma \operatorname{coth}(\gamma T / 2)} \\
\gamma & =\sqrt{(\beta-\pi)^{2}+2 \sigma^{2}} .
\end{aligned}
$$

The stochastic duration is the maturity of a discount bond with the same risk as the coupon bond,

$$
D=\frac{2}{\gamma \operatorname{coth}\left(\frac{2}{\gamma T}-\frac{\pi-\beta}{\gamma}\right)}\left|\frac{\sum C(t) P(t) G(t)}{\sum C(t) P(t)}\right|
$$

where $C(t)$ is the coupon payment (CIR, 1979).

\section{Application of Vasiceks Model}

Another application of the term structure dynamics is to actually see what type of profiles they predict. It makes sense to look first at the profile generated by the simple model by Vasicek (1977). The implementation is done with Mathematica 4 (1999) following the example bv Benninga and Wiener (1998).



Figure 1: Term structure with Vasicek's model. 
The simulation shows the term structure predicted with Vasicek's dynamics. The parameter values are $\alpha=0.12, \beta=-3$ and $\sigma=0.12$. The general profile captures the stochastic nature of the term structure and the presence of predicted negative rates reduces the usefulness of the model.

\section{Conclusion}

In conclusion, there are at least four theories that attempt to explain the profile of the yield curve. These indicate that preferences and investment alternatives are important to investors. The equilibrium and arbitrage approaches develop as a need for a quantitative representation of the term structure. The equilibrium models are more formally structured but required a large amount of information. The arbitrage models may mimic the equilibrium models in some terms but are strongly phenomenological. The simple models capture mainly the dynamics of the level in interest rates. These evolve into two factor models with functionalities for the drift and volatilities of the yield curve. The initial information needed are the initial term structure, and volatility and drift functionalities. The HJM model (1992) is an extension of the ideas in the single and two factor models. This model has elaborate drift and diffusion structure targeted to capture finer details of the term structure. The discussion of Macaulay (1938) and stochastic durations emphasizes the continued applicability of the current scholarly research to practical problems. Simulating the term structure using the Vasicek's model further supports this point and permits to appreciate the actual predicted stochastic behavior with the troublesome negative interest rates. The work could be eventually refined with an assessment of the trade-offs between models reliable predictive capacity of models versus implementation investment.

\section{Acknowledgment}

The collaboration of Professor Scott Mainwaring and the late Professor Albert LeMay at the Helen Kellogg Institute for International Studies, University of Notre Dame, is gratefully acknowledged.

\section{References}

[1] Bali, T. G. (2000) "Stochastic volatility models of the short-term interest rate", Journal of Financial and Quantitative Analysis 35(2): 191-215.

[2] Benninga, S.; Wiener, Z. (1998) "Term structure of interest rates", Mathematica in Education and Research 7(2): 1-9.

[3] Black, F.; Karasinski, P. (1991) "Bond and option pricing when short rates are lognormal", Financial Analyst Journal July-August: 52-59.

[4] Brennan, M. J.; Schwartz, E. S. (1979) "A continuous time approach to the pricing of bonds", Journal of Banking and Finance 3: 133-155.

[5] Brennan, M. J.; Schwartz, E. S. (1980) "Analyzing convertible bonds", Journal of Financial and Quantitative Analysis 15(4): 907-929. 
[6] Chan, K. C.; Karolyi, G. A.; Longstaff, F. A.; Sanders, A. B. (1992) "An empirical comparison of alternative models of the short-term interest rate", Journal of Finance 47(3): 1209-1227.

[7] Chapman, D. A.; Pearson, N. D. (2001) "Recent advances in estimating term-structure models", Financial Analysts Journal July-August: 77-95.

[8] Constantinides, G. M.; Ingersoll, J. E. (1984) "Optimal bond trading with personal taxes", Journal of Financial Economics 13: 299-335.

[9] Cox, J. C.; Ingersoll, J. E.; Ross, S. A. (1979) "Duration and the measurement of basis risk", Journal of Business 59(1): 51-61.

[10] Cox, J. C.; Ingersoll, J. E.; Ross, S. A. (1980) "An analysis of variable rate loan contracts", Journal of Finance 35(2): 389-403.

[11] Cox, J. C.; Ingersoll, J. E.; Ross, S. A. (1985) "A theory of the term structure of interest rates", Econometrica 53(2): 385-406.

[12] Cuthbertson, K.; Nitzsche, D. (2001) Investments: Spot and Derivatives Markets. Wiley, Chichester.

[13] Dothan, L. U. (1978) "On the term structure of interest rates", Journal of Financial Economics 6: $59-69$.

[14] Heath, D.; Jarrow, R.; Morton, A. (1992) "Bond pricing and the term structure of interest rates: a new methodology for contingent claims valuation", Econometrica 60(1): 77-105.

[15] Jeffrey, A. (1995) "Single factor heath-jarrow-morton term structure models based on markov spot interest rate dynamics", Journal of Financial and Quantitative Analysis 30 (4): 619-642.

[16] Longstaff, F. A. (1989) "A non-linear general equilibrium model of the term structure of interest rates", Journal of Financial Economics 23: 195-224.

[17] Longstaff, F. A.; Schwartz, E. S. (1992) "Interest rate volatility and the term structure: a two-factor general equilibrium model", Journal of Finance 47(4): 1259-1282.

[18] Macaulay, F. (1938) Some Theoretical Problems Suggested by the Movement of Interest Rates, Bond Yields and Stock Prices in the United States since 1856. National Bureau of Economic Research, New York.

[19] Merton, R. C. (1973) "Theory of rational option pricing", Bell Journal of Economics and Management Science 4(1): 141-183.

[20] Schaefer, S. M.; Schwartz, E. S. (1994) "A two-factor model of the term structure: an approximate analytical solution", Journal of Financial and Quantitative Analysis 19(4): 413-424.

[21] Schroder, M. (1989) "Computing the constant elasticity of variance option pricing formula", Journal of Finance 44(1): 211-219.

[22] Sundaresan, M. (1984) "Consumption and equilibrium interest rates in stochastic production economics", Journal of Finance 39(1): 77-92.

[23] Vasicek, O. (1977) "An equilibrium characterization of the term structure", Journal of Financial Economics 5: 177-188.

[24] Wolfram Research (1999) Mathematica 4. New York.

[25] Yan, H. (2001) "Dynamic models of the term structure", Financial Analyst Journal JulyAugust: $60-76$. 